\title{
Imagining the next millennium
}

\author{
by Dr. Yvan Hardy ${ }^{1}$
}

It is a daunting proposition to try to envision the next decade, let alone the next millennium. With the notable exception of Marshall McLuhan's global village, the social, economic and political arrangements envisaged by contemporary futurists and science fiction writers have largely failed to materialize. A cautious approach to speculation seems especially warranted in the forest sector, where policy, practice and public opinion are evolving so rapidly that any conjecture about future trends is liable to become obsolete before it even goes to print.

But millennial crystal gazing offers more than an opportunity for future embarrassment. It actually affords an occasion to take stock of the past, come to terms with the present and begin to imagine the kind of future we want. In this respect, the new millennium dawns at a convenient moment for the Canadian Forest Service (CFS), coming as it does on the heels of a year of retrospection occasioned by the 100th anniversary of federal government involvement in forest policy and science.

If the developments of the last century provide any clue about what we might expect in the next, it is simply that we cannot extrapolate the future from the past. It was, after all, the spectre of vanishing forests that prompted the federal government to establish a national forestry service in the first place. Yet forest regeneration has now become such a precise science, and methods of silviculture and harvesting so sophisticated, that Canada's ability to generate timber in perpetuity is beyond dispute.

Predictions about the social and economic future of forests are apt to prove similarly misguided. No one in 1899 could have imagined that in the 100 years it would take for a single Canadian hardwood to reach maturity, forests would be recast from mere objects of commercial exploitation into subjects of proposed international agreements on their sustainability. The last two decades alone have seen a sea of change in Canada's forest sector, from a near total preoccupation with sustained fibre production to a growing concern for nontimber values, such as recreation, environmental systems support, aesthetics and heritage. By 1996, Canadians were spending as much as $\$ 11$ billion a year on forest-related leisure activities like camping and nature photography.

\section{Where We Stand Now}

Yet if the past offers little insight into the future, it at least helps us understand the present. As the federal agency responsible for promoting both the sustainable development of Canada's forests and the competitiveness of Canada's forest industries, the CFS has had to take on a multiplicity of roles and to reshape its agenda repeatedly.

While provincial and territorial governments are responsible for forest management on their Crown lands, the federal role in forestry focuses on science and technology, the environment,

\footnotetext{
${ }^{1}$ Assistant Deputy Minister, Canadian Forest Service
}

international relations, trade and investment, national statistics and Aboriginal affairs. For the CFS this role has crystallized into building consensus among forest stakeholders, shaping domestic and international forest agendas, and generating and transferring the kinds of knowledge needed to safeguard both Canada's forests and its trade suprema-

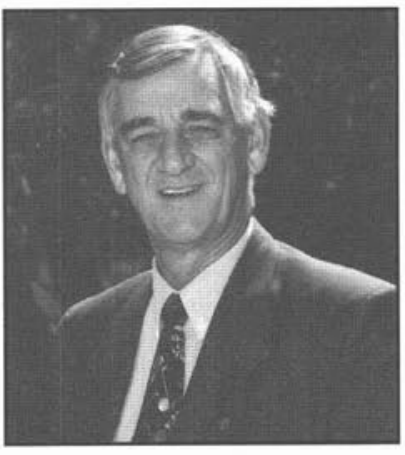
cy in forest products. As more and more voices have joined the policy dialogue and sought to influence the direction of forest research, fulfilling our mandate has demanded greater and greater vision and flexibility. Where once governments could make forest policy somewhat in a vacuum, today the cacophony of voices demanding a say in the debate makes that kind of unilateralism unthinkable.

Moreover, federal public policy is becoming increasingly integrated and programs are designed to be mutually reinforcing. This means that each department pursues not only its own agenda, but also directs a portion of its programming to supporting a common government agenda. For example, the CFS's First Nations Forestry Program makes major contributions to the federal government commitment to enhancing the economic development of Canada's Aboriginal communities.

The myriad challenges created by market liberalization, new methods of wood production, increasing land-use pressures and a shrinking public purse have also upped the ante for collaboration among forest stakeholders. There was a time when industry and environmentalists could afford to be enemies. There was a time when private-sector research institutes and academics could blithely pursue their own agendas. There was a time when government scientists could live in an ivory tower, somewhat isolated from the knowledge needs of professional foresters or the impracticability of transferring the new findings to the field. Those days are gone.

Today's forest research priorities are developed in consultation with provincial and territorial governments, industry representatives, Aboriginal peoples, environmental groups, private woodlot owners and other forest stakeholders. In 1995, following lengthy consultations with Canada's forest community, the CFS reorganized its research operations into 10 national science networks that reflect the priorities and concerns of Canada's forest sector. A new research program was established to study issues related to biodiversity. And CFS research capacity in the areas of climate change and forestry practices was significantly strengthened. In these fast-paced times, organizational adaptability is a necessity and considered a fact of everyday life.

Responding to concerns about the loss of traditional jobs in the forest sector and a growing public interest in new ways of valuing and developing forest resources, the CFS launched a new research program last year with the Natural 
Sciences and Engineering Research Council and the Social Sciences and Humanities Research Council to encourage interdisciplinary approaches to emerging forest issues.

New advisory bodies, such as the National Advisory Board on Forest Research and the Forest Sector Advisory Council, have been established to provide expert advice from outside the federal government. And a Canadian Forest Sector Science and Technology Network has been set up to oversee the implementation, coordination and evaluation of a strategic agenda and course of action developed collectively by leaders from industry, academia, the Aboriginal community, forest research institutes and governments.

\section{Toward Sustainable Forest Management}

With this new focus, the CFS finds itself well placed to design, develop and implement the tools and processes required to expand Canada's knowledge base in sustainable forest management and to provide other federal agencies with scientific and policy advice on forest issues. With a strategic plan that emphasizes capacity building in sustainable forest management practice and the development of analytical tools to measure and define Canada's progress, the CFS is also forging new R\&D relationships with industry, pioneering new technologies and advancing the international policy dialogue on global forest governance.

That dialogue will culminate in April when delegates to the eighth session of the UN Commission on Sustainable Development decide whether to establish an intergovernmental negotiating committee to hammer out the terms of a multilateral treaty on forests. As custodian of 10 percent of the world's forests and as the largest exporter of forest products in the world, Canada has an interest in ensuring the sustainable development of all the world's forests. Through various multilateral fora, from UNCED to the Costa Rica-Canada Initiative, Canada has worked to convince the international community of the need for legally binding standards on sustainable forest management.

The next decade could see not only the proclamation of a multilateral agreement on forests, but also an increasing flow of environmentally sound technologies from developed to developing countries. Canada is already a major exporter of forest protection technologies. Our satellite-based fire-monitoring system, for example, is being used in both Mexico and Malaysia. The government's recent decision to increase foreign aid spending means that developing countries will be able to look increasingly to Canada for the expertise and technology that will allow them to manage their forests more sustainably.

On the domestic front, Canada is gearing up to use satellite-based remote sensing to improve its ability to conduct detailed inventories of its own forests. Such inventories will provide the data needed to set benchmarks and meaningful targets for conservation and protected areas. Forest managers and policymakers will also be able to use the new data to select appropriate locations for intensive crop rotation.

As responsibilities for forest stewardship become codified in international law, Canada will also need reliable ways of assessing its progress and reporting on its performance. To this end, the CFS is continuing to lead refinement and dissemination activities for Canada's framework of criteria and indicators for sustainable forest management-a framework that has been shepherded by the Canadian Council of Forest Ministers.

\section{A Glimpse Ahead}

As global economic integration, population growth and environmental challenges begin forcing governments to reconcile their economic development policies with the global public interest, the very notion of national sovereignty may well be called into question. Hard as it is to imagine, there could come a time when decisions about natural resource development are deemed too important to be left to the discretion of individual governments, even democratic ones. Given the unique and vital functions that forests perform in the global commons, all forest-related policy-making may one day be delegated to an intergovernmental body.

For the foreseeable future, however, Canada will remain in charge of its own forest policy, seeking to protect its forests for future enjoyment without compromising today's economic benefits. Meeting this challenge will take much creativity. While the demand for fibre is growing, so is the scrutiny of consumers into how that fibre is produced. Clearcutting, for example, has become virtually taboo, despite the fact that in many situations it is both operationally and environmentally preferable to other harvesting approaches. Public opposition to synthetic pesticides and herbicides also continues to have an ironic impact on the sector as it forces forest companies to harvest on larger tracts of land to meet their volume requirements. At the same time, however, Canadians are demanding that more land be withdrawn from commercial use. To reconcile these competing pressures, the CFS has been investing heavily in biotechnology research to develop alternatives to synthetic pesticides. But the use of genetically modified insect viruses and disease-resistant trees is not without its share of controversy.

Meanwhile, although world-wide demand for fibre is expected to increase dramatically, new forest competitors with climates that favour fast-growing trees are beginning to monopolize the market. Although Canadian timber is still second to none, solid wood substitutes, such as Parallam and barkboard, are cheaper, stronger and seen as more environmentally friendly than the real thing. And they require only low-quality fibre inputs. With continued advances in engineered wood, the use of real timbers in construction could soon become secondary - the effects of which will force Canada's forestry sector to migrate more rapidly from its reliance on solid timber products. These factors, coupled with the impact of Aboriginal land claim settlements, stringent environmental regulations and new federal government obligations under the Framework Convention on Climate Change, demand a whole new way of thinking about forestry in Canada.

Part of that thinking will need to be about how we want to grow fibre. Already Canadian advances in clonal propagation and tissue culture are speeding up breeding cycles for genetically superior trees. Who knows? We may one day be able to leapfrog the whole planting phase and cultivate two-by-fours in a Petri dish.

In the shorter term, however, some foresters are promoting what is becoming known as the $15 / 15 / 15$ rule: growing trees 15 metres high, $15 \mathrm{~cm}$ in circumference and harvesting them every 15 years. Perhaps such an approach would enable us to sustain an adequate yield of moderate-quality timber without compromising wildlife habitat or the proper functioning of forest ecosystems or the environmental and recreational services that forests perform. On the other hand, it may be that 
we simply need to restructure forest land use, for example, designating 20 percent as protected areas (compared with the current estimated 8 percent), converting another 20 percent into high-yielding plantations, and carefully managing the other 60 percent for a mix of timber production, recreation and wildlife habitat. Commercially viable tree plantations will soon be a reality even in Canada, thanks to advances in biogenetics that now make it possible to grow a marketworthy tree in 20 years.

\section{Our Forest Heritage: Springboard to the Future}

Notwithstanding our world-class forest technologies, our strong voice in international policy-making and our solid grasp of the factors that will influence the future of forests, Canada's forest policy will always be rooted in our past. Forests are integral to Canada's identity, heritage and culture. And because our forest industry is a major engine of the Canadian economy, we must continue to ensure that Canada remains not only a land well endowed with forests, but also a major player in the global forest economy, able to meet the world's insatiable demand for fibre. For the time being, the CFS will be working to accomplish this by engineering faster growing trees, developing better systems for forest management, anticipating and mitigating the effects of climate change, and devising socially acceptable methods of forest protection.

Given how thoroughly we can appreciate the social, political and economic factors affecting forests and forestry, it would be convenient to simply chart a course of action for the next hundred years and put our policy-making and research capacity on automatic pilot. But the volatility of domestic and international developments in the forest arena makes such a plan impracticable. Keeping forest policy responsive requires near-constant adjustments in course. And staying on course means continuing to take our cues from all forest stakeholders, relying on the insight, expertise and good will of the forest community and the visionary capacity of government to ensure that our research and policy priorities serve the interests of Canadians and their forests. 